\title{
Bloating, CTCAE
}

National Cancer Institute

\section{Source}

National Cancer Institute. Bloating, CT CAE. NCI Thesaurus. Code C143322.

A disorder characterized by subject-reported feeling of uncomfortable fullness of the abdomen. 